\title{
What Happened with the Search for the Materia Basis of the Psyche?
}

\author{
Reshetnikov Mikhail* \\ The East-European Psychoanalytic Institute, Saint Petersburg, Russia \\ *Corresponding author: Reshetnikov M, The East-European Psychoanalytic Institute, Saint Petersburg, Russia
}

Submission: 悳 July 28, 2018; Published: 些 August 13, 2018

\begin{abstract}
In this paper, traditional views on the relationship between mental activity and the brain activity are reviewed, and the hypothesis of brain as the biological interface, which was suggested by the author in 2008, is developed. Approaches to research of the psyche in the areas of physiology, psychology, psychotherapy and psychiatry are summarised, and their implications to therapy of patients with mental disorders are analysed. Two models of mental disorders are suggested, which are based on clearer differentiation of organic (the brain-related) pathology and mental disorders as such, which result from informational non-material influence on the psyche as the informational system rather than on the brain. Difference between nervous and psychic functioning of the organism and the personality is outlined; mental activity is viewed as an acquired programmed function, which is formed in a social informational environment. The question of aim of psychopharmacological influence is raised, as well as a number of other questions, which do not have unambiguous answers. The author substantiates the theory of the brain as the biological interface and outlines its historical prerequisites in the literature.
\end{abstract}

Keywords: Biological interface; Information; Brain; Nerves; Psyche

\section{Introduction}

This discovery seemed to be on the surface and it surprises me that nobody made one step forward to integrate reviewed ideas of our predecessors, our own clinical experience developments of contemporary academic science in its approaches to information psychological and psychoanalytic research in child development and observations on feral children on the one hand and criticism of contemporary state of psychology, physiology, psychotherapy and psychiatry crisis of which is caused to significant degree by their outdated approaches to the psyche on the other.

\section{History of the problem}

The problem of the matter and the mind which in a narrower sense is a problem of the relationship between the brain and the psyche has been the most mysterious for two thousand years and is still unresolved. In this paper we will not refer to ideas of outstanding philosophers but rather to practical medicopsychological aspects of the problem. The irrefutable idea that psychic phenomena are intrinsically related to the brain activity had been formulated before Hippocrates, who modified this concept and postulated an idea, which persisted for many centuries, that the brain is a repository of psychic processes. It will be shown that the often-neglected difference between the two formulations is crucial. Despite the impressive progress of research in the area, Hippocrates's hypothesis has dominated the field in physiology, psychiatry and psychology and even in psychotherapy - for two thousand years. The only exception is psychoanalysis, which views the psyche as an epiphenomenon due to Sigmund Freud's insights.

Let me remind you that after unsuccessful attempts to develop The Project for a Scientific Psychology 1894-1895 to explain psychic phenomena on the basis of physiological processes and reactions, Freud abandoned this idea and objected publishing this unfinished work. Moreover, Freud declared that he was unable to find physiological bases of the psyche [1,2] and stated his intention to deal only with the psyche as such and to consider the psyche an epiphenomenon. Freud was not the first who tried to find material basis of the psyche, but the only one who instantly understood that it was a stalemate. In the XVI century, ideas of Hippocrates were further developed by Rene Descartes 1596-1659, the author of the idea of reflex, who wrote: "I am now dissecting heads of different animals in order to find out, what is imagination, memory, etc" [3].

Let us omit a few less known names and come closer to nowadays. In 1863, Sechenov IM wrote a paper An Attempt to Bring Physiological Basis to Psychic Processes and wanted to publish it in a popular journal Sovremennik edited by Russian poet Nekrasov $\mathrm{N}$. However, the censorship forbade to publish this paper in the literary miscellany (although it was appropriate), explaining that it propagated materialism and could offend feelings of religious believers. In result, the paper was published in a reputable journal 
Medical Bulletin under a different title Reflexes of the Brain [4]. I think that if materialism had not been so fashionable at that time, this purely speculative paper would not have been published at all. Let me quote some of so-called arguments that Sechenov [4] used to support his ideas: "For us as physiologists it is enough to say that the brain is an organ of the soul, which means a mechanism that was set in motion by some causes and leads to a number of external phenomena characteristic for psychic activity"... "Thus, the brain, which is the organ of the soul, can make some movements under certain conditions (according to the concepts of the school) in a determined way, that is, it acts like any other machine..."... "A reader can understand that all characteristics of external manifestations of the brain activity, without exception... result from some degree of contraction of a group of muscles, which is known as a purely mechanical act" [4]. After this theoretical generalization, supported only by his experiments with chemical irritation of frogs' medulla by crystal salt as a basis of concepts of "excitation" and "inhibition" in the central nervous system, the author makes a very important statement: "Finally, I need to confess that while formulating these hypotheses, I had almost no acquaintance with psychological literature" [4].

The next historical attempt to develop physiological psychology was undertaken by Wundt [5], who published three volumes of The Fundamentals of Physiological Psychology in 1874. In this work Wundt [5] relies upon developments in physiology of senses and suggests a strategic program of development of psychology with two main directions: physiological (or experimental) and social (or cultural-historical) psychology [5]. Unfortunately, the academic psychology, that claims to belong to natural sciences, has developed in frames of experimental approach. Cultural-historical direction, which Wundt [5] described as analysis of products of the human spirit has been implemented only in psychoanalysis, while social psychology has been concentrated at general laws of human behaviour, activity and interaction, and different manifestations of personality in these interactions. The notion of spirit was introduced to contemporary science only ten years ago and appeared not in psychology but in psychotherapy.

Our outstanding compatriot, the first Russian winner of the Nobel Prize Pavlov [6] read Reflexes of the Brain while studying in seminary in Ryazan, and this book changed his life profoundly, as he put it. The influence of this work can be seen in every physiological research carried out by I.P. Pavlov, who was a brilliant scientist and the author of such concepts as conditional reflex, higher psychic activity and the second signal system [6]. Without detailed analysis of unique discoveries by I.P. Pavolv, we will mention that his experimental study of the Higher Nervous Activity (HNA) was limited to study of the salivary glands in dogs. In the beginning, Pavlov [6] resisted any attempts to psychological interpretation of his physiological experiments and observations and forbade his assistants to speak in such terms as "the dog has understood $\backslash$ wanted $\backslash$ wished etc."

However, later the idea of reflexes was uncritically applied to the psyche, mostly by the academician's students and followers. The very idea of such application, though, was supported by Pavlov
[6] himself, who thought that the reflex unites ("identifies") the physiological and the psychic, and he considered the HNA as an equivalent of psychic activity [6,7]. However, we can admit that only 5 out of almost 350 scientific works by Pavlov [6] address the area of psychology and psychiatry. In the end of his life, I.P. Pavlov modestly admitted: "I am not a clinician, I have always been a physiologist, and it is too late for me to become a clinician now", - and that is why, he continues, "I do not dare claim that I am competent enough, from clinicians' perspective, to discuss the relevant material" [6]. One more quote from I.P. Pavlov: “... I want to warn against misunderstanding of my views. I do not deny psychology as understanding of a person's inner world [6]. In general, we should admit that there is no more psyche in reflex than in a light bulb connected to a movement detection sensor that flashes every time a moving objects appears.

What happened later? Let us remember key stages in development of contemporary scientific ideas. Due to theories by Sechenov [4] and Pavlov [6], three new areas of knowledge developed at the edge of psychology and physiology: they were physiology of Higher Nervous Activity (HNA), psychophysiology and neurophysiology. It is important that all these fields, after almost a century of attempts to explain any psychic activity by excitation and inhibition reactions, reflexive activity, electric activity of the brain and biochemical reactions, restricted the area of their interests, with exception of very few authors, with study of certain brain structures as the basis for psychic activity. Let us stress it once again, that they mean not "psychic structures" as earlier, but rather the brain structures as the basis for psychic activity. However, in psychiatry and psychopharmacology, and to some degree in psychotherapy, all approaches to psychopathology are based on established HNA theory, which still views psyche and brain structures and mechanisms as identical and directly addresses anatomical structure of the nervous system, localization of functions in the brain cortex, transmitting pathways and biochemical reactions related to neurotransmitter exchange in the synaptic cleft. There are certain historical, methodological and ideological reasons for it [8].

\section{Where does search for material structures of the psyche lead}

After the middle of the XIX century, and in accordance with the spirit of that time and super-popular ideas of primitive materialism, Sechenov [4] and Pavlov [6] and other outstanding authors were united by the intention to find material basis for psychic activity. In the last two centuries, these specialists searched for the psyche in gyros, cortex, ventricles of the brain, subcortical brain, electric, wave and quantum activity of the brain [4-7,9-13], and finally: "What a miracle! It has been found in the synaptic cleft!" [8]. It should be mentioned that in any epoch, dominating hypotheses of psychic structures would influence therapy of mental disorders. Anatomical approach to "psychic structures" gave rise to ideas of lobotomy and callosum dissection; the concept of electric activity resulted in thousand experiments with electroconvulsive treatment; historically new biochemical theories led to development of psychopharmacology as a new area in chemical industry, the 
main target of which is the synaptic cleft. Nowadays, therapy of mental disorders is based predominantly on psychopharmacology, which aims at regulation of neurotransmitters exchange in the synaptic cleft and thus, supposedly, at the psyche. But the question whether these current methods of therapy actually lead to the patients' cure is still unresolved, as even the authors of these methods report $20-40 \%$ of placebo effect, while side effects of most psychopharmacological medications include the whole list of psychopathology, intellectual and emotional dullness, as well as deteriorated reproductive function and disturbed functioning of liver, kidneys, hormonal system etc.

\section{Substantiation of the author's hypothesis}

In 2008, the author developed hypothesis of the brain as the biological interface $[3,14-17]$ as a counterbalance to these traditional views. This hypothesis compares the brain with the computer hardware, on the one hand, and the psyche with the software, on the other; the process of language acquisition, upbringing and education of the child can be thus viewed as a kind of programming. It should be stressed that the programming requires a specific language, like in technical systems. Let me remind that. Jacque Lacan suggested the idea that a child, from his first days of life, immerses into "the bath of language", which determines his psychic development [18]. Thus, psychic activity is viewed as a kind of informational exchange that evolves and is maintained only in society, and physical and physiological phenomena as bodily symptoms of the soul, providing indirect information about one's thoughts, ideas and experiences as well as about psychic contents in general. These symptoms merely show that something is going on with the subject, but we can only guess, what exactly it is. It resembles a situation of a man standing near a high impenetrable fence of a factory and trying to conclude what is being produced based on unclear noise that he can hear.

The main point of the hypothesis that I suggested in 2008 was the following: with time, the special role of the brain will be reconsidered, and in a new framework, it will be assigned a more modest but nevertheless important role of a link between the ideal and the ideal, or, speaking in contemporary terms, of the biological interface [3]. In this respect, previously popular attempts to explore human thinking and psychic activity by means of the EEG can be compared with measuring voltage and resistance of a TV set to know the content of the programs. Psychic activity is currently knowable only by means of self-observation and reflection, the methods that were characterized as idealistic, subjective and nonscientific for long time of development of psychology; however, the attitude to these methods of self-awareness has recently started to change.

\section{The academic science on information}

Further development of the hypothesis was related to a very important idea that had been neglected by psychologists, physiologists and psychiatrists for long time and had not been taken into account in their theoretical constructs. The academic science is currently viewing information as a non-material factor, so that only its carriers (biological, paper, electronic etc.) are material [19-22]. However, non-material information acquires a number of qualitative and quantitative characteristics, which is did not initially possess. It can be neutral, emotionally valent, scaring, correct or incorrect etc., but all these characteristics appear only within a perceiving subject, as different subjects would have different reactions to the same information (such as reactions to September 11, 2001, mourning in the US and elated crowds in Livia). By itself, carrier-based information does not exist in the absence of a subject. I have repeatedly noticed that my colleagues feel confused by this idea. I have suggested them to carry out an experiment: they might dissemble their computer and try to find any programs or any kind of information inside it. Let me remind you definition given by the founder of cybernetics Wiener [23] information is neither matter nor energy, information is information.

Only alive beings, especially human beings, can be subjects of perception, as well as producers, carriers, keepers and verifiers of any information. In the process of evolution, homo sapience have gradually created more and more reliable systems of storing and transmitting growing amount of information to the future generations: from primitive forms of communication, typical for animals, to human speech; from primitive naming of things or actions to abstract concepts and generalizations; from only spoken transmission of knowledge to writing; from myths to scientific knowledge; from clay tablets and papyrus to contemporary informational systems. Here we can refer to brilliant idea by I.P. Pavlov on the second signal system, but it should be mentioned that, in contrast to the first signal system that is based on reflex activity and is common for humans and animals (is determined genetically), the second signal system is an artificial construct (of informational nature) and is formed only in society. Taking this into account, we can agree that contemporary notion of evolution, resulting from synthesis of two exclusively biological approaches, classical Darwinism and populational genetics, should be significantly widened to include informational- psychological aspects.

\section{Fallacies that distort scientific truths}

The common view of the brain as the repository of all psychic functions has led to many misperceptions that permeate our everyday language; in science, they caused the well-known phenomenon of "theoretical overload", when everything beyond the dominating theory is rejected. There are such well-known phrases as "it's getting on his nerves", although nerves are just transmitters; or "the idea has come into my head", although it is mind rather than head, etc. In general, both layman perception and scientific knowledge identify the nervous with the psychic.

In the same vein, contemporary human sciences completely neglect crucial differences between the nervous system and the psyche. There are a few of such differences, and the most important one is the following: healthy psyche differentiates imaginary stimuli from real ones, while nervous system reacts almost in the same way to them both. This is the basis for all suggestive and auto-suggestive techniques, when, for instance, one imagines that his hand is in hot water, and temperature of his palm skin 
increases, or he imagines that he is running 100 meter race, and his heart rate increases. Very few specialists, however, with the exception of psychotherapists, take into account that this is also true for development of psychosomatic pathology, which develops in accordance with one's individual system of symbolization (in our terms, "inner psychic programming"). What one "takes to his heart" might result in cardio-logical disease; offence that he cannot "swallow" might influence the real swallowing and cause bulimia or anorexia; being short of breath after shocking news might lead to asthma attacks; an event that one "cannot withstand" might result in joint pains.

In general, individual system of psychic traumata symbolization functions in the same way as repetitive suggestion (or, more correctly, autosuggestion). One can agree or disagree with this idea, but I suppose that even people who are far from psychotherapy and psychology have seen someone who was literally bent down by unbearable psychological (informational) burden. When we speak of symbolization, we need to remember Sigmund Freud and his scientific discovery made due to observation of experiments by Jean Charcot with suggestion-caused paralyses. A suggestion-caused paralysis affected not real zones of innervation, as it is the case with real paralyses, but the patient's arm in general, as she - a person without medical education - could perceive it. Freud formulated his conclusion rather cautiously but it can be formulated in a more concrete way (here is our formulation): it is not true that the nervous system controls the psyche but rather the psyche controls the nervous system including the central nervous system.

\section{The brain is also the soma}

The idea of the psyche influencing somatic functions formulated by J. Heinroth in 1818 was revolutionary and contradicted the idea of "brain-based structures of the psyche", that is why it was not accepted by official science for long time (more than 100 years) and existed only at the laymen level. When medical doctors were trying in vain to determine aetiology of a disease, the patient or his relatives would easily conclude that he became ill "because of grief" or "because of unreciprocated love". Gradual recognition of psychosomatic pathology should have refuted the idea, which had dominated medical science, that psychic phenomena are identical to their material carriers such as brain and its physiological and biochemical processes; in psychosomatic approach, the latter become secondary in relation to psyche. However, this discovery seemed to stay unnoticed by psychiatry and medicine in general.

The influence of the psyche on the soma was finally recognized in the XX century, but approaches to treatment of mental disorders that were applied for two thousand years have not changed and still use chemical (psychopharmacological) influence on somatic brain structures, thus implying that the psyche is just a product of the brain, like bile is a product of liver. The idea that the brain in relation to the psyche is just the soma, albeit important kind of it will not be recognized soon, as I think, despite abundant clinical evidence supporting it. Let us add, without detailed explanations, that the idea of "the brain plasticity" will in time be transformed into the idea of the psyche plasticity, because tissue, however highly organized, cannot intentionally change itself; for that, higher level of regulation in tissue processes is required.

\section{Freud's fore-knowledge}

Let us turn once again to Freud [1]. At the time when Freud lived and created psychoanalysis, information was not a scientific category yet. The notion of cybernetics was introduced in 1948 when Wiener [23] published his book cybernetics or control and communication in the animal and the machine and only after that, qualitatively new approach to information was formed. So Freud could not use the concept but he managed to foresee it. Let us remember the lecture that Freud [1] gave in the Vienna Medical Society in 1895. Freud speaks about intense emotions and says that a vivid impression, positive or negative one, increases "something" in the psyche that he calls "the sum of excitations" and that belongs to the psyche but not to the brain. Just like Winer discerns information as a separate category and stresses that it is neither matter nor energy, Freud discerns the psyche as a separate category that is neither matter nor energy. It can be seen when Freud extrapolates (rather than just applies) the energy conservation law to the psyche and formulates the law of conservation of psychic contents (not in the brain, not in the nervous centres, not in the synapses but in different psychic structures). According to this law, any new psychic content (we would call it "information" now), once entering the psyche, will never disappear but can transform into another psychic contents including pathological ones. In order to avoid misunderstanding, let us add that the energetic component is also included in Freud's theory, but it is related not to psychic contents but rather to libido. Speaking about words, Freud also mentions that they (together with non-verbal manifestations of reactions) are the only observable equivalent of inner experiences, and he stresses that words can substitute for actions. In this respect, Freud's approach is closer to Pavlov's [6] ideas of the second signal systems, related to sign, that is informational although I.P. Pavlov also did not use this later term. As a digression from the main topic of the paper, let us remind you that brilliant works of our outstanding compatriot on conditional reflex and principles of backward afferentation (prototype and analogue of the feedback principle) became the starting point for development of cybernetics. I would like to make one more remark: in contrast to the artificial intelligence, in which certain programs and parameters are given, and results of analysis and synthesis are relatively precise and easy to predict, human intelligence is able of self-development, unpredictable and subjective in its perception of information and makes non-standard and variable decisions. The other difference is that information that damages normally functioning psyche can come from outside, like a computer virus, or generated by the psyche itself in form of fallacious ideas, experiences, suspicions, etc., which become selftraumatizing factors.

We need to address the heritage of Sigmund Freud now. He drew parallels between psychic and physical trauma and wrote: "psychic trauma or memory of it acts like a foreign body, which after getting inside (the psyche-MR) persists as an active factor for rather long time" [1]. 


\section{Additional arguments: Feral children and abandoned children}

Let us outline additional arguments supporting the theory discussed above. Studies of feral children (also known as Mowgli children) showed that normal human psyche, as well as bipedalism, does not develop without early immersion in social environment (or, as mentioned earlier, without language programming of the child's brain by social environment). We can conclude that the healthy brain is a necessary but not sufficient prerequisite of development and adequate functioning of the human psyche, and language programming is still required. Due to the fact that instincts and reflexes are functional in feral children, they should be understood as genetically determined, in contrast to conscious activity, which is an acquired function and can develop only in social informational environment.

Let me add that feral children adopt their behavioural programs and language as a system of informational exchange from an animal community in which they survived, and it also supports the ideas that I develop here. There are well-known cases of feral children studied by psychologists: the children could only speak the language of wolves or dogs or birds (as in the case of a child who lived not with his disturbed parents but surrounded by parrots). This confirms the author's hypothesis that the process of upbringing and education is a version of programming and imprinting. Let me remind you that imprinting is defined as a psychophysiological mechanism, by which behavioural patterns that are perceived by senses (visual, audial, olfactory etc.) are rigidly fixed in memory after minimal exposure. This mechanism is characteristic for both humans and animals, but it works only in the early childhood.

As it was mentioned in the literature $[7,19]$ if feral children stayed in an animal community for long time, they would reproduce behaviour of their "adopted parents", and it could not be changed by psychologists and specialists in rehabilitation working with them. These children aptly use all four extremities for movement; they sniff their food before eating it and prefer raw meat which they obtain by hunting for chickens and small rodents; in case of thirst, they lick their lips and lap water instead of drinking it; they are repelled by the daylight; they do not recognize themselves in a mirror, exactly like animals. They run away from other people and from the fire, and in a situation of danger they would take threatening bodily positions and start roaring; they urinate and defecate like animals. This kind of behaviour is quite natural. A more peculiar characteristic that should be mentioned is their inability to laugh, despite normal innervation and mimic muscles.

There were many studies of a "social smile" in infants, and one more conclusion is to be made: an individual without society does not smile and will not respond to a smile; can we imagine the world without smiles? Natural animal instincts are activated in such an individual, which are dormant in everyone and are ready to rise any time when cultural frames come apart. There is abundant support to this idea. For instance, it is a well-known story of a girl who developed normally until her severely disturbed parents made her live with their dog in a kennel, from 3 to 8 years of her age; thus, the child, who had already acquired bipedalism and speech, started using four extremities to move, barking, howling, devouring her food and lapping water in a manner of her "adopted mother". It can be understood as a deep regression due to the absence of parental figures and separation from the culture.

Considering the fact that it is so easy to reactivate primitive behavioural patterns suppressed by culture, current tolerant attitude to various manifestations of non-formal and deviant behaviour, starting from the beginning of the XX century, needs to be thoroughly reviewed.

\section{The second group of additional arguments}

It would be rather strange not to mention works by Luria AR, specifically The Small Book about Large Memory [20]. In this book Luria describes a mnemonist Sherechevsky SV, whom he observed for many years, and proves that the psyche functions as hi-tech video recorder that records everything a person has ever seen or heard. Otto Petzl, one of Freud's followers, showed in his classic experiments on subliminal perception [19] that our eye sees more and the ear hears better than we can consciously perceive, and thus subliminal stimuli can influence judgements, behaviour and decision making. One more factor supporting informational theory of the psyche is recent studies in so called mirror neurons $[21,22]$ that transmit information and simultaneously receive non-verbalized information (thoughts). This way of nonverbal communication might be crucial for herd animals, allowing thousands of them to react simultaneously at danger signal, as well as for predators hunting together (otherwise it is impossible to explain how wolves or lions share the roles of "beaters" chasing the prey and those who wait for it in an ambush). The same kind of communication might be used by ants, thus thousands of insects put mutual effort into moving their prey, which is thousand times bigger and heavier that they are, in a certain direction.

\section{What are the obstacles to new approaches?}

There are still popular theories that address psychic structures, anatomical, physiological, physical or physical-chemical ones. There are at least two explanations of this fact. First, I am sure that many colleagues of mine after reading this material will feel a kind of cognitive dissonance. These ideas contradict what we were taught, what we used to believe, what we based our scientific generalizations on, what we applied for our therapeutic approaches and strategies. The author had also struggled with such dissonance. The second reason is commercialization of medicine, such as multibillion investments in development and advertisement of new psychopharmacological medications and theories popularizing biochemical concepts of the psyche and possibility to treat mental disorders by psychopharmacology. The fact that no single patient with a severe psychopathology was cured by these means does not influence strategic direction in medication-based treatment of mental disorders. It can be concluded that this search for chemistry of thoughts and feelings will persist, despite the stalemate is has come to. This search can be best characterised with a saying that 
is popular in scientific community: "However much effort you put into dissembling the radio, you won't find the music inside!".

\section{On the main philosophical question}

In relation to the theory discussed here, the main philosophical question is formulated in its traditional version: the matter is primary and the subject is primary, but the consciousness is secondary, because the consciousness develops only in a society as an informational non-material structure. This structure is impossible without subjects transmitting and receiving information.

In conclusion, let me remind you that the concept of "the main philosophical question" was suggested by F. Engels in his work Ludwig Feuerbach and the End of Classical German Philosophy in 1886. Some thinkers of the past and the present consider this question unimportant, artificial and lacking epistemic meaning. However, we should admit that its importance has increased significantly in our informational epoch. Moreover, its formulation and solution influence a possibility to obtain adequate knowledge about the world. Many outstanding thinkers, such as Plato, Leibnitz, Hegel etc., claimed that the world of ideas exists independently from our consciousness, and the world of things is just its incarnation [23]. Contemporary informational technologies require qualitatively new approaches to these problems, as our reality convincingly proves us that the world of ideas can be developed artificially by making qualitative change in the existing cultural codes. Thus, it is possible to artificially create certain trends and vectors of development of the international community directed at elevated culture and scientific progress or propelling interethnic conflicts, terrorism, commodity fetishism and sacralisation of material success.

\section{Conclusion}

\section{The essence of the discovery and the theory}

It has been proved here, in contrast to previous explanations of psychic activity by material structures (e.g., brain tissues, electrical, wave or quantum activity, chemical reaction or neurotransmitter exchange in the synaptic cleft), that the healthy brain is a necessary but not sufficient precondition for psychic functioning of personality. The brain and the psyche are two interrelated but different systems. The brain is a material structure, on which the psyche is based, and the psyche is non-material, as it is a specific version of informational processes in a biological system.It has been shown that the brain is the biological interface, a kind of screen for projecting information about external world and the person himself, including information about his inner mental processes. On the other hand, the brain is also an operational system and a biological server, accumulating, storing and reproducing information, which can be transmitted only through social environment on the basis of language programming of the brain. Acquiring a new language helps to form an additional informational system of the psyche; it is confirmed by clinical observations in psychiatric practice showing that in an acute phase of a mental disorder some bilingual patients lose ability to speak their mother tongue but can adequately communicate with their therapist in another language. The first such case was famously described by Freud [1] in his work Studies of Hysteria 1895.

\section{References}

1. Freud S (2005) Studies of hysteria. The East-European Psychoanalytic Institute, Russia, p. 454

2. Hubel DH, Wiesel TN (2005) Brain and visual perception: the story of 25-year collaboration. Oxford University Press, USA, p. 106.

3. Reshetnikov MM (2008) Mental disorder. The East-European Psychoanalytic Institute, Saint Petersburg, Russia, p. 272.

4. Sechenov IM (2015) Reflexes of the brain. MIT Press, USA, p. 352.

5. Wundt W (2007) An introduction into psychology. M Kom Kniga, p. 166.

6. Pavlov IP (1951) Physiology and psychology in studying high nervous activity of animals. Moscow, Russia, pp. 323-340.

7. Danilova NN, Krilova AL (2005) Physiology of high nervous activity. Phoenix, USA, p. 478.

8. Lapin IP, Oxenkrag GF (1969) Intensification of the central serotoninergic processes as a possible determinant of thymoleptic effect. Lancet 1(7586): 132-136.

9. Anuashvili AN (2008) An objective psychology on the base of wave's model of the brain. Ekon-Inform,p. 292.

10. Laborit H (1969) Neurophysiologie, aspects metaboliques et pharmacologiques. Paris, France.

11. Nikandrov VV (2007) Psychology. Prospect, pp. 396-397.

12. Nicolls D, Martin P (2017) From neuron to brain. In: Wallas B, Fuks $P$ (Eds.), URRC: Book-House Libercom, pp. 453-454.

13. Petrovsky VA (1992) Psychology of non-adaptive activity. Moscow, Russia, p. 45.

14. Reshetnikov MM (2011) Critical post-materialism in psychology and psychiatry. Neurological Bulletin 43(2): 66-69.

15. Reshetnikov MM (2012) Modern tendencies of development of psychology and psychiatry. Journal Psychotherapy Moscow, pp. 7-15.

16. Reshetnikov MM (2017) Problem of relation between brain and mind in physiology, medicine and psychology. Journal of Psychiatry and Psychiatric Disorders 1(6): 313-316.

17. Reshetnikov MM (2017) What is the Psyche? What are we curing? Journ Anthropology 6(3): 11-15.

18. Lacan J (1953) Function and field of speech and language in psychoanalysis. Report at the Rome' Congress, Institute of psychology of the Rome University, Gnozis, Moscow, Russia.

19. Godfrua ZH (1996) What is Psychology (2 ${ }^{\text {nd }}$ edn). 1: 496.

20. Luria AR (1968) The small book about large memory. Moscow, Russia.

21. Rizzolatti G, Fadiga Z, Gallese V, Fogassi L (1996) Premotor cortex and the recognition of motor actions. Cognitive Brain Research 3(2): 131141.

22. Rizzolatti G, Fogassi L, Gallese V (2006) Mirrors in the mind. Scientific American Band, pp. 30-37.

23. Wiener N (1968) Cybernetics or control and communication in the animal and the machine $\left(2^{\text {nd }} e d n\right)$. MIT Press Cambridge, Massachusetts, USA, p. 325 . 
Creative Commons Attribution 4.0 International License

For possible submissions Click Here

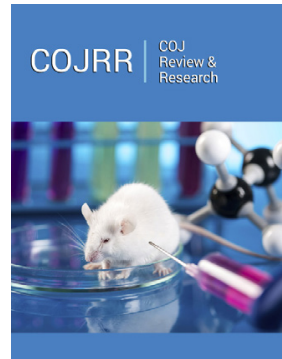

\section{COJ Reviews \& Research}

\section{Benefits of Publishing with us}

- High-level peer review and editorial services

- Freely accessible online immediately upon publication

- Authors retain the copyright to their work

- Licensing it under a Creative Commons license

- Visibility through different online platforms 